\title{
A Preliminary Study of Different Treatment Strategies for Anxious Depression
}

\author{
Yun Wang,' Xiaohua Liu, ${ }^{2,3}$ \\ Daihui Peng, (D) ${ }^{2}$ Yan Wu, ${ }^{2}$ \\ Yun'ai Su, (D) ${ }^{4}$ jia $X u{ }^{5}$ \\ Xiancang $\mathrm{Ma},{ }^{6}{ }^{6} \mathrm{Yi} \mathrm{Li}^{7}$ \\ Jianfei Shi, ${ }^{8}$ \\ Xiaojing Cheng, \\ Han Rong, ${ }^{10}$ \\ Yiru Fang (iD 1,3, I I \\ 'Division of Mood Disorders, Shanghai \\ Mental Health Center, Shanghai Jiao Tong \\ University School of Medicine, Shanghai, \\ People's Republic of China; ${ }^{2}$ Department of \\ Psychiatry, Shanghai Mental Health Center, \\ Shanghai Jiao Tong University School of \\ Medicine, Shanghai, People's Republic of \\ China; ${ }^{3}$ Shanghai Key Laboratory of \\ Psychotic Disorders, Shanghai Mental Health \\ Center, Shanghai Jiao Tong University School \\ of Medicine, Shanghai, People's Republic of \\ China; ${ }^{4}$ Department of Psychiatry, Peking \\ University Sixth Hospital, Peking, People's \\ Republic of China; ${ }^{5}$ Department of \\ Psychiatry, Harbin First Specific Hospital, \\ Harbin, People's Republic of China; \\ ${ }^{6}$ Department of Psychiatry, The First \\ Affiliated Hospital of Xi'an Jiao Tong \\ University, Xi'an, People's Republic of China; \\ ${ }^{7}$ Department of Psychiatry, Wuhan Mental \\ Health Center, Wuhan, People's Republic of \\ China; ${ }^{8}$ Department of Psychiatry, \\ Hangzhou Seventh People's Hospital, \\ Hangzhou, People's Republic of China; \\ ${ }^{9}$ Department of Psychiatry, Shandong Mental \\ Health Center, Shandong, People's Republic \\ of China; ${ }^{10}$ Department of Psychiatry, \\ Shenzhen Kangning Hospital, Shenzhen, \\ People's Republic of China; "CAS Center \\ for Excellence in Brain Science and \\ Intelligence Technology, Shanghai, People's \\ Republic of China
}

Correspondence: Daihui Peng; Yiru Fang Email pdhsh@I26.com;

yirufang@aliyun.com
Background: Despite the best treatments, about $20 \%$ of patients with major depressive disorder (MDD) receiving drugs and psychological intervention show little or no improvement. There is no trial comparing different treatment methods in patients with anxiety/somatic subtype MDD.

Aim: To compare the efficacy and safety of various treatments in patients with anxiety/ somatic subtype MDD.

Methods: This was a preliminary multicenter randomized controlled trial at eight participating hospitals in China (09/2016-06/2019) (ClinicalTrials.gov \#NCT03219008). The patients were randomized to mirtazapine/SNRIs, mirtazapine/SNRIs+cognitive behavioral therapy (CBT), mirtazapine+SNRIs, or mirtazapine+SNRIs+physical therapies (modified electroconvulsive treatment or repetitive transcranial magnetic stimulation). The primary endpoint was the 17-item Hamilton Depression Scale (HAMD-17). The Quick Inventory of Depressive Symptomatology-Self-Report (QIDS-SR) and Quality of Life (QOL)-6 were the secondary endpoints. The adverse events (AEs) were monitored. The patients were assessed at baseline ( 0 weeks), and at the end of the $2 \mathrm{nd}, 4 \mathrm{th}, 6 \mathrm{th}, 8 \mathrm{th}$, and 12 th week during treatment.

Results: Finally, 107 patients were included: mirtazapine/SNRIs ( $\mathrm{n}=36)$, mirtazapine/SNRIs + CBT $(n=28)$, mirtazapine+SNRIs $(n=29)$, and mirtazapine+SNRIs+physical therapies $(n=14)$. The 17-HDRS and QIDS-SR scores decreased in all four groups, and the QOL-6 scores increased. There were no differences in the 17-HDRS ( $\mathrm{P}=0.099)$, QIDS-SR ( $\mathrm{P}=0.407)$, and QOL-6 $(\mathrm{P}=0.485)$ scores among the four groups. There were no differences in the occurrence of AEs among the four groups $(\mathrm{P}=0.942)$.

Conclusion: This preliminary trial suggests that all four interventions (mirtazapine/SNRIs, mirtazapine/SNRIs+CBT, mirtazapine+SNRIs, or mirtazapine+SNRIs+physical therapies) achieved similar response and remission rates in patients with anxiety/somatic subtype MDD. The safety profile was manageable.

Keywords: major depressive disorder, anxiety, mirtazapine, serotonin-norepinephrine reuptake inhibitor, cognitive behavioral therapy, Hamilton Depression Scale

\section{Introduction}

The prevalence of major depressive disorder (MDD) is approximately $6 \%$ per year worldwide, with a lifetime prevalence of $20 \%,{ }^{1}$ making MDD among the most common mental health issues. The specific subtypes of depression have treatment and prognostic implications and include melancholic depression (melancholia), depression with atypical features, MDD with psychotic features, MDD with catatonia, and MDD with anxious distress. ${ }^{1-4}$ MDD is refractory in about $15 \%$ of patients and recurrent in about $35 \%$ of patients, and the risk of recurrence increases with each additional episode of major depression. ${ }^{1-5}$ 
Anxious distress requires at least two of the following features being present most of the days of an MDD episode: a sense of being "keyed up" or tense, unusual restlessness, difficulty concentrating due to worry, fear that awful things may happen, and worry about losing selfcontrol. ${ }^{1-4}$ MDD with anxious distress is characterized by depression caused by unrelenting anxiety and will cause further anxiety, forming a vicious circle. ${ }^{1-4}$ Chronic diseases are associated with anxiety and depression. ${ }^{6,7}$ MDD and anxiety are associated with psychosomatic conditions, such as burning mouth syndrome. ${ }^{8}$ In the months preceding the MDD episode, prodromal symptoms may include anxiety, panic attack, and phobias. ${ }^{3}$ Anxious distress is associated with a higher likelihood of reporting suicidal thoughts and less response to traditional antidepressants. $^{1-4}$

Mirtazapine is a tetracyclic used for the treatment of MDD. ${ }^{3}$ Mirtazapine can antagonize central presynaptic $\alpha_{2}$ adrenergic autoreceptors and alloreceptors, and specifically block $5-\mathrm{HT}_{2}$ and $5-\mathrm{HT}_{3}$ on the postsynaptic membrane. ${ }^{9}$ Serotonin-norepinephrine reuptake inhibitors (SNRIs) can also be used for the management of MDD with anxious distress. ${ }^{3}$ Cognitive-behavioral therapy (CBT), particularly problem-solving therapy, helps alleviate the depressive and anxious symptoms by questioning and challenging the patients' irrational thinking and wrong attitude towards themselves, the surrounding environment, and the future, and by managing the sources of anxiety. ${ }^{10,11} \mathrm{CBT}$ can be used with drugs for the management of an acute episode. ${ }^{10}$ Physical therapies such as modified electroconvulsive treatment (MECT) or repetitive transcranial magnetic stimulation (rTMS) can also be applied for managing MDD and anxiety distress. ${ }^{12-15}$

Despite the best treatments, about $20 \%$ of patients with MDD receiving drugs and psychological intervention show little or no improvement. ${ }^{1-4}$ Mirtazapine has therapeutic effects on depressive disorders with anxiety agitation or somatic symptoms. ${ }^{3}$ Meanwhile, SNRIs can simultaneously impact the norepinephrine and 5-HT axes, which is more effective for patients with MDD of the anxiety/somatic subtype. ${ }^{3}$ Nevertheless, currently, there is no randomized controlled trial (RCT) research that compares various treatments in patients with MDD and anxiety/somatic discomfort.

Therefore, the objective of the present study was to compare the efficacy and safety of various treatments in patients with MDD of the anxiety/somatic subtype. The results could provide data for the personalized management of MDD.

\section{Methods}

\section{Study Object and Design}

This was a preliminary multicenter randomized controlled trial that enrolled patients with first-episode MDD or patients with acute-stage MDD but without systemic treatment in at the Psychiatry Departments of the eight participating hospitals (Supplementary Table S1) between September 2016 and June 2019. The trial was approved by the ethics committee of the Shanghai Mental Health Center (lead center) and by the ethics committees of all other participating hospitals. Written informed consent forms were obtained from all patients. This trial was registered (ClinicalTrials.gov \# NCT03219008). This study complies with the Declaration of Helsinki.

The inclusion criteria were: 1) 18-55 years of age; 2) patients with anxiety/somatic MDD who met the DSM-5 diagnostic criteria ${ }^{16}$ and were currently in a major depression episode (MDE); 3) in the acute phase with first episode or recurrence; 4) 17-item Hamilton Depression Scale (HAMD-17) $\geq 17$ points; and 5) did not take any antidepressants and received no physical or psychological treatment within 6 months before enrollment. The criteria for determining the anxiety/somatic subtype were: depression/undermotivation and atypical symptoms were scored using IDS (The Inventory of Depressive Symptomatology), anxiety somatization factors were scored using the HAMD scale, and symptom weights were calculated to determine the main clinical subtypes of patients. ${ }^{16}$

The exclusion criteria were: 1) with serious physical diseases (history of brain trauma or cerebrovascular accident, narrow-angle glaucoma, epilepsy, myocardial infarction, unstable angina, congestive heart failure, severe cirrhosis, acute and chronic renal failure, severe diabetes, aplastic anemia, moderate and severe malnutrition and other serious physical diseases including neurological, cardiac, liver, kidney, endocrine or hematological system or other diseases that might interfere with the trial (abnormal index was more than twice the upper limit of normal)); 2) HAMD-17 item 3 (suicide) $>3$, or suicide attempt during this episode; 3) pregnant or lactating women, or planning pregnancy; 4) with comorbid psychotic disorders or with psychotic symptoms, substance abuse/dependence (except nicotine), previous episode of mania or 
hypomania, mental retardation, personality disorders, or anorexia nervosa/bulimia; or 5) secondary depressive disorders caused by other organic or drug substances.

\section{Treatment and Grouping}

All subjects were randomly divided into four groups according to the treatment methods: 1) mirtazapine/ SNRIs; 2) mirtazapine/SNRIs + CBT; 3) mirtazapine + SNRIs; and 4) mirtazapine + SNRIs + physical therapy. The randomization was achieved using a central computer system programmed and maintained by a third-party statistician.

The choice of the treatment regimen, mirtazapine, SNRI, and dosages were all at the physicians' discretion. SNRIs included duloxetine (Cymbalta, Euprolol, and Oxpin) and venlafaxine (Enoxin and Boroxin). The physical therapy included MECT or rTMS, with 10 times a month for a MECT course and 10 times over two weeks for an rTMS course. Each treatment regimen was continuously performed for 8-12 weeks.

\section{Observation Index and Data Collection}

The patients' age, sex, ethnicity, body mass index (BMI), education level, occupation, marital status, total depressive course, duration of this depressive episode, and severity of depression were collected. The assessment scales used in the present study included the $17-\mathrm{HDRS},{ }^{17}$ the Quick Inventory of Depressive Symptomatology-Self-Report (QIDS-SR) scale, ${ }^{18}$ Quality of Life (QOL-6), and a log of the adverse events (AEs). Those questionnaires were validated in Chinese. ${ }^{19,20}$

\section{Endpoints}

The primary endpoint was the reduction rate of 17-HDRS scores in the intention-to-treat set. A reduction of the 17HDRS scores by $\geq 50 \%$ was considered as a response. A total score of $17-\mathrm{HDRS} \leq 7$ was considered as a remission. The scores of QIDS-SR and QOL-6 were the secondary endpoints.

\section{Follow-Up}

The treatments lasted 8-12 weeks. The patients were assessed at baseline ( 0 weeks), and at the end of the $2 \mathrm{nd}$, 4 th, 6th, 8th, and 12th week during treatment. The followup included efficacy and safety index, 17-HDRS, QIDSSR, QOL-6, adverse event log, clinical symptomatology assessment, blood biochemistry, protein, neuroimaging, and neuroelectrophysiological examination. The followup time window was \pm 2 days.

\section{Safety Assessment}

The adverse reactions included gastrointestinal reactions (stomach discomfort, diarrhea, constipation, nausea, vomiting, bitter taste, dry mouth, and increased appetite), abnormal liver function, dizziness and headache (including headache, dizziness, vertigo, and syncope), fatigue (including sleepiness, fatigue, lethargy, and slow response), allergy, tremor (including tremor, shaking hand, foot shaking, weakness, fatigue, muscle weakness, night sweating, dyspnea, nervousness, and restlessness), heart rate changes (including bradycardia and tachycardia), suicide self-injury (including self-injury, suicide attempt, and irritability), and general adverse reactions (including nosebleeds, alopecia, pneumonia, and fever).

\section{Statistical Analysis}

This was a preliminary study, and no power analysis was performed.

All data were analyzed using SPSS 22.0 (IBM, Armonk, NY, USA) and GraphPad Prism 6 (GraphPad Software, San Diego, US). All continuous variables were tested for normality using the Kolmogorov-Smirnov test. The continuous variables with a normal distribution were presented as means \pm standard deviations and analyzed using ANOVA and the Bonferroni method for pair-wise comparison. The continuous variables with a non-normal distribution were presented as medians (interquartile ranges (IQRs)) and analyzed using the Kruskal Wallis test. Categorical data were presented as number (percentage) and analyzed using the chi-square test or Fisher's exact test. All tests were two-sided (except the chi-square test), and P-values $<0.05$ were considered statistically significant.

\section{Results}

\section{Characteristics of the Participants}

A total of 163 patients were screened for eligibility and 21 were excluded. Then, 142 were randomized to the mirtazapine/SNRIs $(n=40)$, mirtazapine/SNRIs+CBT $(n=35)$, mirtazapine+SNRIs $(n=34)$, and mirtazapine+SNRIs+physical therapies $(n=33)$. During treatment, 35 participants dropped out. Finally, 107 patients were included in the analyses: mirtazapine/SNRIs $(n=36)$, mirtazapine/SNRIs 
+CBT ( $\mathrm{n}=28)$, mirtazapine+SNRIs $(\mathrm{n}=29)$, and mirtazapine+SNRIs+physical therapies $(n=14)$.

Table 1 presents the characteristics of the participants. There were no differences among the four groups regarding the demographic, socioeconomic, and clinical characteristics (all $\mathrm{P}>0.05$ ).

\section{Efficacy Evaluation}

The 17-HDRS scores were decreased in all four groups at the end of treatment (all $\mathrm{P}<0.05$ ). There were no differences in the 17-HDRS scores among the four groups at the end of treatment $(\mathrm{P}=0.099)$, nor in the response rates (ie, 17 -HDRS decreasing by $\geq 50 \%$ ) $(\mathrm{P}=0.149)$ or the remission rates (ie, 17-HDRS scored 57) $(\mathrm{P}=0.166)$. The QIDS-SR scores were decreased in all four groups at the end of treatment. The QOL-6 scores were increased in all four groups at the end of treatment. There were no differences in the QIDS-SR $(\mathrm{P}=0.407)$ and $\mathrm{QOL}-6(\mathrm{P}=0.485)$ among the four groups at the end of treatment (Table 2 and Figure 1).

\section{Safety}

There were no differences in the occurrence of AEs among the four groups $(\mathrm{P}=0.942)$ (Table 3$)$.

Table I Baseline Data for Each Treatment Regimen Group in Patients with MDD and Anxiety/Somatic Discomfort

\begin{tabular}{|c|c|c|c|c|c|}
\hline Indicators & $\begin{array}{l}\text { Mirtazapine/ } \\
\text { SNRIs }(n=36)\end{array}$ & $\begin{array}{l}\text { Mirtazapine/SNRIs } \\
+ \text { CBT }(n=28)\end{array}$ & $\begin{array}{l}\text { Mirtazapine + } \\
\text { SNRIs }(n=29)\end{array}$ & $\begin{array}{l}\text { Mirtazapine + SNRIs + } \\
\text { Physicotherapy }(n=14)\end{array}$ & $\mathbf{P}$ \\
\hline Age (years) & $28.5(22,43.5)$ & $28(23.5,34)$ & $30(25,42)$ & $29(24,37)$ & 0.664 \\
\hline $\begin{array}{l}\text { Sex, n (\%) } \\
\text { Male } \\
\text { Female }\end{array}$ & $\begin{array}{l}13(36.1 \%) \\
23(63.9 \%)\end{array}$ & $\begin{array}{l}4(14.3 \%) \\
24(85.7 \%)\end{array}$ & $\begin{array}{l}10(34.5 \%) \\
19(65.5 \%)\end{array}$ & $\begin{array}{l}4(28.6 \%) \\
10(71.4 \%)\end{array}$ & 0.235 \\
\hline $\begin{array}{l}\text { Ethnic group, n (\%) } \\
\text { Han } \\
\text { Others }\end{array}$ & $\begin{array}{l}35(97.2 \%) \\
\text { I (2.8\%) }\end{array}$ & $\begin{array}{l}27(96.4 \%) \\
\mathrm{I}(3.6 \%)\end{array}$ & $\begin{array}{l}28(96.6 \%) \\
\text { I (3.4\%) }\end{array}$ & $\begin{array}{l}14(100 \%) \\
0\end{array}$ & $>0.999$ \\
\hline Body mass index $\left(\mathrm{kg} / \mathrm{m}^{2}\right)$ & $20.8(19.5,22.7)$ & $21.4(18.7,23.1)$ & $20.8(19.5,23.2)$ & $20.6(19.2,22.3)$ & 0.980 \\
\hline $\begin{array}{l}\text { Marital status, n (\%) } \\
\text { Unmarried } \\
\text { Married/cohabiting } \\
\text { Divorce/Separation }\end{array}$ & $\begin{array}{l}20(55.6 \%) \\
14(38.9 \%) \\
2(5.6 \%)\end{array}$ & $\begin{array}{l}15(53.6 \%) \\
12(42.9 \%) \\
1(3.6 \%)\end{array}$ & $\begin{array}{l}11(37.9 \%) \\
18(62.1 \%) \\
0\end{array}$ & $\begin{array}{l}7(50 \%) \\
6(42.9 \%) \\
\text { I (7.1\%) }\end{array}$ & 0.464 \\
\hline $\begin{array}{l}\text { Occupation, n (\%) } \\
\text { On-the-job } \\
\text { Retired } \\
\text { Student } \\
\text { Unemployed } \\
\text { Educational level }\end{array}$ & $\begin{array}{l}19(52.8 \%) \\
0 \\
9(25 \%) \\
8(22.2 \%) \\
15(9.5,16)\end{array}$ & $\begin{array}{l}20(71.4 \%) \\
0 \\
5(17.9 \%) \\
3(10.7 \%) \\
16(15,16)\end{array}$ & $\begin{array}{l}18(62.1 \%) \\
\text { I (3.4\%) } \\
9(31 \%) \\
\text { I (3.4\%) } \\
16(12,17)\end{array}$ & $\begin{array}{l}8(57.1 \%) \\
0 \\
4(28.6 \%) \\
2(14.3 \%) \\
15(12,16)\end{array}$ & $\begin{array}{l}0.378 \\
0.134\end{array}$ \\
\hline $\begin{array}{l}\text { Duration of total depression } \\
\text { (years) }\end{array}$ & $7(2.125,49)$ & $3(2,12)$ & $12(2,48)$ & $6.5(3,17)$ & 0.270 \\
\hline $\begin{array}{l}\text { Duration of this depressive } \\
\text { episode (months) }\end{array}$ & $8(4,20.5)$ & II $(6,24)$ & $8(4,12)$ & $12(6,26.5)$ & 0.310 \\
\hline $\begin{array}{l}\text { Depression severity, n (\%) } \\
\text { Not assessed } \\
\text { Normal, disease-free } \\
\text { Marginality } \\
\text { Mild psychosis } \\
\text { Moderate psychosis } \\
\text { Obvious psychosis } \\
\text { Severe psychosis } \\
\text { Most severe psychosis }\end{array}$ & $\begin{array}{l}0 \\
0 \\
0 \\
3(8.3 \%) \\
14(38.9 \%) \\
16(44.4 \%) \\
3(8.3 \%) \\
0\end{array}$ & $\begin{array}{l}0 \\
0 \\
0 \\
2(7.1 \%) \\
12(42.9 \%) \\
11(39.3 \%) \\
3(10.7 \%) \\
0\end{array}$ & $\begin{array}{l}\text { I (3.4\%) } \\
0 \\
0(0 \%) \\
2(6.9 \%) \\
14(48.3 \%) \\
10(34.5 \%) \\
2(6.9 \%) \\
0\end{array}$ & $\begin{array}{l}0 \\
0 \\
0 \\
0 \\
4(28.6 \%) \\
7(50 \%) \\
3(21.4 \%) \\
0\end{array}$ & 0.887 \\
\hline
\end{tabular}

Abbreviations: SNRI, serotonin-norepinephrine reuptake inhibitor; CBT, cognitive behavioral therapy. 
Table 2 Efficacy Evaluation Results of Each Treatment Group at the Last Follow-Up

\begin{tabular}{|c|c|c|c|c|c|c|}
\hline Indicators & & $\begin{array}{l}\text { Mirtazapinel } \\
\text { SNRIs }(n=36)\end{array}$ & $\begin{array}{l}\text { Mirtazapine/ } \\
\text { SNRIs + CBT } \\
(n=28)\end{array}$ & $\begin{array}{l}\text { Mirtazapine + } \\
\text { SNRIs }(n=29)\end{array}$ & $\begin{array}{l}\text { Mirtazapine + SNRIs + } \\
\text { Physicotherapy }(n=14)\end{array}$ & $\mathbf{P}$ \\
\hline $\begin{array}{l}\text { Primary } \\
\text { endpoint }\end{array}$ & $\begin{array}{l}\text { I7-HDRS } \\
\text { Response (I7-HDRS score } \\
\text { reduction } \geq 50 \%), n(\%) \\
\text { Remission (I7-HDRS total } \\
\text { score } \leq 7), n(\%)\end{array}$ & $\begin{array}{l}10(4,16.5) \\
23(63.9 \%) \\
16(44.4 \%)\end{array}$ & $\begin{array}{l}7.5(3,15) \\
18(64.3 \%) \\
17(60.7 \%)\end{array}$ & $\begin{array}{l}10(6,15) \\
17(58.6 \%) \\
12(41.4 \%)\end{array}$ & $\begin{array}{l}5(1,9) \\
13(92.9 \%) \\
10(71.4 \%)\end{array}$ & $\begin{array}{l}0.099 \\
0.149 \\
0.166\end{array}$ \\
\hline $\begin{array}{l}\text { Secondary } \\
\text { endpoint }\end{array}$ & $\begin{array}{l}\text { QIDS-SR } \\
\text { QOL-6 }\end{array}$ & $\begin{array}{l}7(5,12) \\
20(18,22)\end{array}$ & $\begin{array}{l}7(2.5,12) \\
21(19,24)\end{array}$ & $\begin{array}{l}8(5,12) \\
21(19.5,22.5)\end{array}$ & $\begin{array}{l}5.5(0,11) \\
21(18,24)\end{array}$ & $\begin{array}{l}0.407 \\
0.485\end{array}$ \\
\hline
\end{tabular}

Abbreviations: SNRI, serotonin-norepinephrine reuptake inhibitor; CBT, cognitive behavioral therapy; I7-HDRS, I7-item Hamilton Depression Rating Scale; QIDS-SR, Quick Inventory of Depressive Symptomatology - Self-Reported (QIDS-SR); QOL, quality of life.

\section{Discussion}

About $20 \%$ of patients with MDD receiving drugs and psychological intervention show little or no improvement despite various treatments. ${ }^{1-4}$ Currently, there is no trial comparing different treatment strategies in patients with anxiety/somatic subtype MDD. Therefore, the aim of this preliminary study was to compare the efficacy and safety of various treatments in patients with anxiety/somatic subtype MDD. The results strongly suggest that all four interventions (mirtazapine/SNRIs, mirtazapine/SNRIs
+CBT, mirtazapine+SNRIs, and mirtazapine+SNRIs $+\mathrm{MECT} / \mathrm{rTMS}$ ) achieved similar response and remission rates while the safety profile was manageable.

First-line drugs for the management of anxiety include selective serotonin reuptake inhibitors (SSRIs), SNRIs, and pregabalin, and second-line drugs include imipramine, bupropion, benzodiazepines, buspirone, hydroxyzine, and quetiapine. ${ }^{3}$ Mirtazapine is also among the drugs that can be used for the treatment of anxiety disorders, as well as MDD, making a drug of choice for the management of

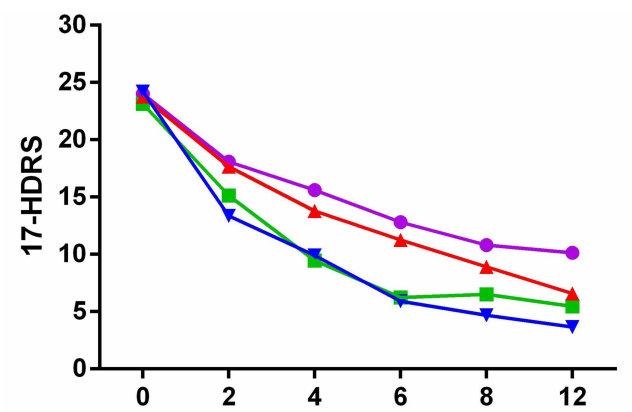

A

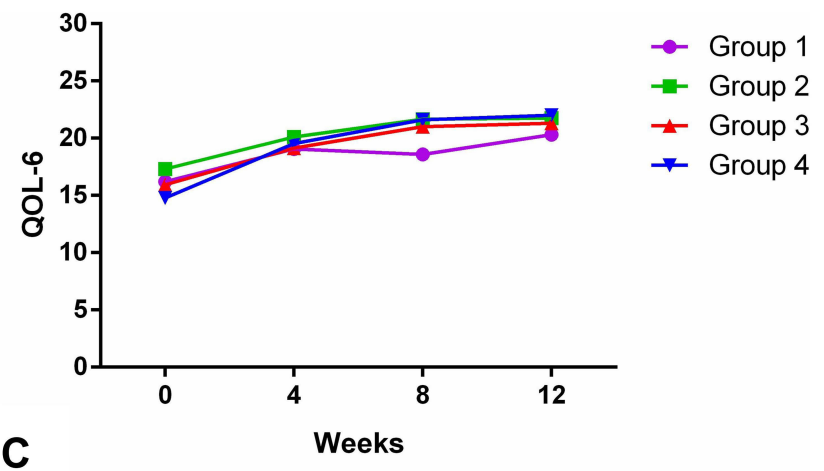

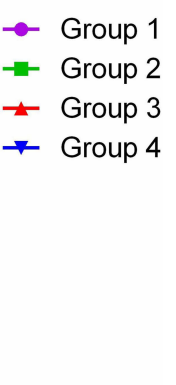

Weeks

B

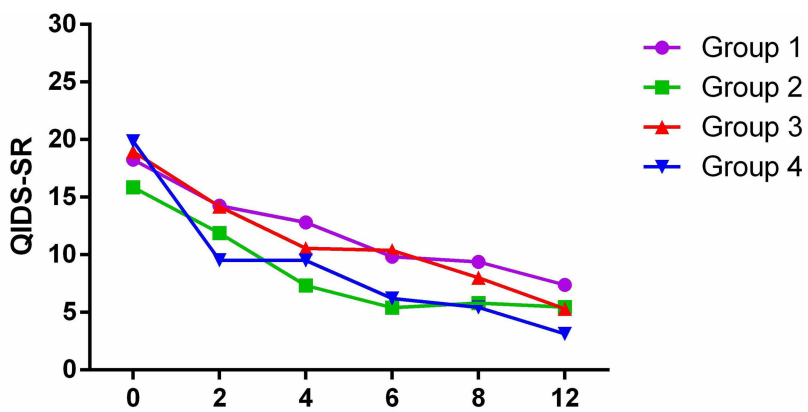

Weeks

Figure I Observation indexes over the course of the I2-week treatment in patients with anxious depression. (A) 17-item Hamilton Depression Rating Scale (17-HDRS). (B) Quick Inventory of Depressive Symptomatology - Self-Reported (QIDS-SR). (C) Quality of life (QOL)-6. 
Table 3 Total Number of Adverse Reaction Records

\begin{tabular}{|c|c|c|c|c|c|}
\hline Indicators & $\begin{array}{l}\text { Mirtazapinel } \\
\text { SNRIs }(n=36)\end{array}$ & $\begin{array}{l}\text { Mirtazapine/ } \\
\text { SNRIs + CBT } \\
(n=28)\end{array}$ & $\begin{array}{l}\text { Mirtazapine + } \\
\text { SNRIs }(n=29)\end{array}$ & $\begin{array}{l}\text { Mirtazapine + SNRIs + } \\
\text { Physicotherapy }(n=14)\end{array}$ & $\mathbf{P}$ \\
\hline Adverse events, $n$ (\%) & $6(16.7 \%)$ & $4(14.3 \%)$ & $4(13.8 \%)$ & I (7.I\%) & 0.942 \\
\hline Gastrointestinal dysfunction & 0 & 0 & $2(6.9 \%)$ & I (7.I\%) & 0.135 \\
\hline Abnormal liver function & 0 & 0 & 0 & 0 & I \\
\hline Headache & I (2.8\%) & $2(7.1 \%)$ & I (3.4\%) & 0 & 0.742 \\
\hline Fatigue & I (2.8\%) & $2(7.1 \%)$ & I (3.4\%) & 0 & 0.742 \\
\hline Allergy & 0 & 0 & 0 & 0 & 1 \\
\hline Tremor & 4 (II.I\%) & I (3.6\%) & 0 & 0 & 0.199 \\
\hline Tachycardia/ bradycardia & I (2.8\%) & 0 & 0 & 0 & $>0.999$ \\
\hline Self-harm & I (2.8\%) & 0 & 0 & 0 & $>0.999$ \\
\hline Common & 0 & 0 & 0 & 0 & I \\
\hline
\end{tabular}

Abbreviations: SNRI, serotonin-norepinephrine reuptake inhibitor; CBT, cognitive behavioral therapy.

MDD of the anxiety/somatic subtype. ${ }^{3,21}$ SNRIs also have some efficacy for the management of MDD with anxiety. ${ }^{3,22,23}$ In addition, psychotherapy and CBT can be used to manage MDD, as well as the causes in which is rooted the anxiety, breaking the vicious circle of anxiety and MDD. ${ }^{10,11}$ As complementary therapies, MECT and rTMS have been shown to be effective in MDD, but are not used alone for the management of MDD. ${ }^{12-15}$

Nevertheless, achieving a meaningful clinical response using a single therapy is considered to be relatively uncommon, leading to the need for combined therapies. $^{24}$ There is a theoretical advantage of using a second drug with a complementary mode of action. In the present study, even though all four treatment strategies improved the 17-HDRS, QIDS-SR, and QOL-6 indexes, there were no differences among the four strategies at the end of treatment. This is supported by Kessler et al, ${ }^{25}$ who showed that adding an SNRI on mirtazapine did not improve the outcomes in patients with refractory MDD. Other studies report conflicting results. $^{26-29}$ A review highlighted the small amount of evidence for combination strategies for the treatment of MDD. ${ }^{30}$ Of course, the conflicting results could be due to a variety of factors, including the selection of the patients, the dosages, and socioeconomic, familial, and spiritual factors.

Mirtazapine, SNRIs, MECT, and rTMS are considered safe and well-tolerated in patients with MDD. ${ }^{3,4,9,12-15,31}$ There were no differences in the occurrence of AEs among the four groups. All AEs were manageable, and none led to self-harm or death.
This study has limitations. This was a preliminary trial with a small sample size, which was not confirmed by a power analysis. In addition, the drop-out rate was high, especially in the group receiving physical therapies. Finally, the dosages were left at the physicians, discretion instead of being determined by a strict protocol. This could have biased the results. In addition, socioeconomic and spiritual factors were not taken into account in the analyses.

In conclusion, the results of the present preliminary trial strongly suggest that all four interventions (mirtazapine/ SNRIs, mirtazapine/SNRIs+CBT, mirtazapine+SNRIs, and mirtazapine+SNRIs+MECT/rTMS) achieved similar response and remission rates in patients with anxiety/somatic subtype MDD. The safety profile was manageable.

\section{Data Sharing Statement}

The corresponding authors (pdhsh@126.com; yirufang@aliyun.com) intend to share individual deidentified participant data. We intend to share specific data on all cases. We will provide all required research documents. You can access the data at: https://www.ncmi.cn/dataSearch/certifi cate_search.html. These services are permanently available.

\section{Acknowledgments}

The authors acknowledge the help of all the study participants.

\section{Funding}

This study was funded by the National Key Research and Development Project (2016YFC1307100). 


\section{Disclosure}

All authors declare that they have no competing interests.

\section{References}

1. Otte C, Gold SM, Penninx BW, et al. Major depressive disorder. Nat Rev Dis Primers. 2016;2:16065. doi:10.1038/nrdp.2016.65

2. Davidson JR. Major depressive disorder treatment guidelines in America and Europe. J Clin Psychiatry. 2010;71(Suppl E1):e04. doi:10.4088/JCP.9058se1c.04gry

3. American Psychiatric Association. Practice Guideline for the Treatment of Patients with Major Depressive Disorder. 3rd ed. Philadelphia: American Psychiatric Association; 2010.

4. Thase ME. The multifactorial presentation of depression in acute care. J Clin Psychiatry. 2013;74(Suppl 2):3-8. doi:10.4088/ JCP.12084su1c.01

5. Gili M, Roca M, Armengol S, et al. Clinical patterns and treatment outcome in patients with melancholic, atypical and non-melancholic depressions. PLoS One. 2012;7:e48200. doi:10.1371/journal. pone. 0048200

6. Siegmann EM, Muller HHO, Luecke C, et al. Association of depression and anxiety disorders with autoimmune thyroiditis: a systematic review and meta-analysis. JAMA Psychiatry. 2018;75:577-584. doi:10.1001/jamapsychiatry.2018.0190

7. Mitchell AJ, Ferguson DW, Gill J, Paul J, Symonds P. Depression and anxiety in long-term cancer survivors compared with spouses and healthy controls: a systematic review and meta-analysis. Lancet Oncol. 2013;14:721-732. doi:10.1016/S1470-2045(13)70244-4

8. Galli F, Lodi G, Sardella A, Vegni E. Role of psychological factors in burning mouth syndrome: a systematic review and meta-analysis. Cephalalgia. 2017;37:265-277. doi:10.1177/0333102416646769

9. Alam A, Voronovich Z, Carley JA. A review of therapeutic uses of mirtazapine in psychiatric and medical conditions. Prim Care Companion CNS Disord. 2013;15. doi:10.4088/PCC.13r01525

10. Driessen E, Hollon SD. Cognitive behavioral therapy for mood disorders: efficacy, moderators and mediators. Psychiatr Clin North Am. 2010;33:537-555. doi:10.1016/j.psc.2010.04.005

11. Chibanda D, Weiss HA, Verhey R, et al. Effect of a primary care-based psychological intervention on symptoms of common mental disorders in zimbabwe: a randomized clinical trial. JAMA. 2016;316:2618-2626. doi:10.1001/jama.2016.19102

12. Lisanby SH. Electroconvulsive therapy for depression. $N$ Engl J Med. 2007;357:1939-1945. doi:10.1056/NEJMct075234

13. Ottosson JO, Odeberg H. Evidence-based electroconvulsive therapy. Acta Psychiatr Scand. 2012;125:177-184. doi:10.1111/j.16000447.2011.01812.x

14. Lefaucheur JP, Andre-Obadia N, Antal A, et al. Evidence-based guidelines on the therapeutic use of repetitive transcranial magnetic stimulation (rTMS). Clin Neurophysiol. 2014;125:2150-2206.

15. Bersani FS, Minichino A, Enticott PG, et al. Deep transcranial magnetic stimulation as a treatment for psychiatric disorders: a comprehensive review. Eur Psychiatry. 2013;28:30-39. doi:10.1016/j.eurpsy.2012.02.006

16. American Psychiatric Association. Diagnostic and Statistical Manual of Mental Disorders (DSM-5). Philadelphia: American Psychiatric Association; 2013.

17. Bobo WV, Anglero GC, Jenkins G, et al. Validation of the 17-item Hamilton Depression Rating Scale definition of response for adults with major depressive disorder using equipercentile linking to Clinical Global Impression scale ratings: analysis of Pharmacogenomic Research Network Antidepressant Medication Pharmacogenomic Study (PGRN-AMPS) data. Hum Psychopharmacol. 2016;31:185-192.
18. Rush AJ, Trivedi MH, Ibrahim HM, et al. The 16-Item Quick Inventory of Depressive Symptomatology (QIDS), clinician rating (QIDS-C), and self-report (QIDS-SR): a psychometric evaluation in patients with chronic major depression. Biol Psychiatry. 2003;54:573-583. doi:10.1016/S0006-3223(02)01866-8

19. Liu J, Xiang YT, Wang G, et al. Psychometric properties of the Chinese versions of the Quick Inventory of Depressive Symptomatology - Clinician Rating (C-QIDS-C) and Self-Report (C-QIDS-SR). J Affect Disord. 2013;147:421-424. doi:10.1016/j. jad.2012.08.035

20. Zheng YP, Zhao JP, Phillips M, et al. Validity and reliability of the Chinese Hamilton Depression Rating Scale. $B r \quad J$ Psychiatry. 1988;152:660-664. doi:10.1192/bjp.152.5.660

21. Katzman MA, Bleau P, Blier P, et al. Canadian clinical practice guidelines for the management of anxiety, posttraumatic stress and obsessive-compulsive disorders. BMC Psychiatry. 2014;14(Suppl 1): S1. doi:10.1186/1471-244X-14-S1-S1

22. Slee A, Nazareth I, Bondaronek P, et al. Pharmacological treatments for generalised anxiety disorder: a systematic review and network meta-analysis. Lancet. 2019;393:768-777. doi:10.1016/S01406736(18)31793-8

23. Li X, Zhu L, Zhou C, et al. Efficacy and tolerability of short-term duloxetine treatment in adults with generalized anxiety disorder: a meta-analysis. PLoS One. 2018;13:e0194501. doi:10.1371/journal. pone. 0194501

24. Moret C. Combination/augmentation strategies for improving the treatment of depression. Neuropsychiatr Dis Treat. 2005;1:301-309.

25. Kessler DS, MacNeill SJ, Tallon D, et al. Mirtazapine added to SSRIs or SNRIs for treatment resistant depression in primary care: Phase III randomised placebo controlled trial (MIR). BMJ. 2018;363:k4218. doi:10.1136/bmj.k4218

26. Carpenter LL, Yasmin S, Price LH. A double-blind, placebo-controlled study of antidepressant augmentation with mirtazapine. Biol Psychiatry. 2002;51:183-188. doi:10.1016/S00063223(01)01262-8

27. Blier P, Gobbi G, Turcotte JE, et al. Mirtazapine and paroxetine in major depression: a comparison of monotherapy versus their combination from treatment initiation. Eur Neuropsychopharmacol. 2009;19:457-465. doi:10.1016/j.euroneuro.2009.01.015

28. Blier P, Ward HE, Tremblay P, et al. Combination of antidepressant medications from treatment initiation for major depressive disorder: a double-blind randomized study. Am J Psychiatry. 2010;167:281-288. doi:10.1176/appi.ajp.2009.09020186

29. Rush AJ, Trivedi MH, Stewart JW, et al. Combining medications to enhance depression outcomes (CO-MED): acute and long-term outcomes of a single-blind randomized study. Am J Psychiatry. 2011;168:689-701. doi:10.1176/appi.ajp.2011.10111645

30. Lopes Rocha F, Fuzikawa C, Riera R, Ramos MG, Hara C. Antidepressant combination for major depression in incomplete responders-a systematic review. J Affect Disord. 2013;144:1-6. doi:10.1016/j.jad.2012.04.048

31. Silverstone PH. Qualitative review of SNRIs in anxiety. J Clin Psychiatry. 2004;65(Suppl 17):19-28. 


\section{Publish your work in this journal}

Neuropsychiatric Disease and Treatment is an international, peerreviewed journal of clinical therapeutics and pharmacology focusing on concise rapid reporting of clinical or pre-clinical studies on a range of neuropsychiatric and neurological disorders. This journal is indexed on PubMed Central, the 'PsycINFO' database and CAS, and is the official journal of The International Neuropsychiatric Association (INA). The manuscript management system is completely online and includes a very quick and fair peer-review system, which is all easy to use. Visit http://www.dovepress.com/testimonials.php to read real quotes from published authors.

Submit your manuscript here: https:/www.dovepress.com/neuropsychiatric-disease-and-treatment-journal 